\title{
Disaster Management in a Nephrology Service: Lessons Learned from Hurricane Maria
}

\author{
Melvin Bonilla-Félix Marta Suárez-Rivera \\ Pediatric Nephrology Section, University of Puerto Rico, Medical Sciences Campus, San Juan, Puerto Rico
}

\section{Keywords}

Disaster management · Dialysis $\cdot$ Hurricane $\cdot$ Natural disasters

\section{Abstract}

Background: Puerto Rico suffered a major humanitarian crisis after Hurricane Maria. We describe our experience with patients with renal disease in an academic medical center. Summary: A comprehensive emergency response plan should be developed, shared and discussed with the team and the patients prior to the hurricane. The needs of the staff should not be ignored to ensure their ability to participate as responders. Physical damage to facilities, lack of basic services, shortage of disposable products, and the inability to get to treatment centers are the most common threats. Preemptive dialysis can avoid serious complications. A contingency plan to move patients to another center should be prearranged in case the unit is rendered nonfunctional after the storm. Patients must receive preventive education about fluid and dietary restrictions and the possible use of potassium binding drugs if they cannot reach a dialysis unit. A list of alternative drugs that could be used if

\section{KARGER}

(c) 2018 S. Karger AG, Basel

E-Mail karger@karger.com

www.karger.com/bpu patients are not able to fill their medications is required. The Internet and social media proved to be an invaluable communication tool. A registry of patients with updated contact information, as well as contact information for relatives and a physical address where an emergency rescue team can be dispatched is essential. Water safety should be reinforced. Key Message: Our experience showed us that preparing for the worst is not enough. Advanced planning of a streamlined response is the best tactic to decrease harm.

(C) 2018 S. Karger AG, Basel

On September 20, 2017 Hurricane Maria, a category 4 hurricane, made landfall in Puerto Rico with $150 \mathrm{mph}$ $(240 \mathrm{~km} / \mathrm{h})$ sustained winds. Some category 5 winds were reported in the higher elevations of the island. About 70,000 homes were destroyed and $80 \%$ of the electrical poles were knocked down [1]. Hurricane Maria took off-line $85 \%$ of the cell phone towers. Many communities were isolated from the outside world for weeks [2]. Although the initial death toll reported by the government was 64 people, a study estimated the excess 
deaths within the 4 months after the passing of hurricane Maria at 4,645 people [3]. A more recent study by Milken Institute of Public Health at The George Washington University estimated a total excess mortality of 2,975, similar to the death toll reported after the terrorist attack at the World Trade Center on September 11, 2001 [4]. This makes hurricane Maria the worst natural catastrophe in Puerto Rico in the last century and the second deadliest hurricane in US history, with a higher death toll than hurricane Katrina. The risk of death associated with hurricane Maria was $45 \%$ higher for populations living in low socioeconomic municipalities and in males older than 65 years of age [4]. This is not surprising as natural disasters typically disproportionately affect the most vulnerable populations such as the poor, children, elders, and people with chronic illnesses. For several months Puerto Rico suffered a major humanitarian crisis due to lack of primary services, such as electricity and tap water. This manuscript describes our experience in Puerto Rico and the lessons learned in the main academic medical center on the island, focusing on our experience with pediatric patients with chronic renal disease. In Puerto Rico, we did not observe any pediatric patients who developed acute kidney injury as a direct result of the hurricane; therefore, this discussion will focus on the management of patients with preexisting renal disease.

\section{Preparedness}

Disaster management begins with the preparation steps taken prior to the impact of the natural disaster. This requires a comprehensive analysis of resources, focusing on the identification of vulnerabilities, followed by the development of a structured emergency response plan that must be shared and discussed extensively with the entire response team and the patients. In addition to the short-term plans made in the few days prior to landfall, a continuous evaluation of infrastructure is essential as part of long-term planning, especially in areas vulnerable to storm surge. In the case of academic healthcare facilities, although quickly reestablishing clinical services should be the priority, additional care should be given to guarantee the continuity of research and educational activities. The needs of personnel should not be ignored, as their welfare is essential to ensuring their ability to participate as responders. In the last 3 years, the Puerto Rico Emergency Preparedness and Response Activities Renal Coalition was organized through our Renal Network 3. This coalition is composed of all the agencies related to end-stage renal disease (ESRD) care, including pediatric ESRD. Although we had been preparing for years, there were challenges beyond our predictions. The renal coalition proved to be instrumental, as we were connected throughout the event using social media and could help each other. Table 1 shows an emergency preparedness checklist that can help dialysis units to organize their response, decreasing harm to their patients.

Patients with ESRD are extremely vulnerable after natural disasters. Direct physical damage to healthcare facilities, lack of electric power and tap water, shortage of disposable products, and the inability to get to treatment centers are some of the most remarkable threats. Providing early dialysis in advance of the disaster is the first step. This prevents missed treatments and reduces rush in the dialysis unit after the hurricane. Preemptive dialysis can help patients avoid serious complications such as hyperkalemia and fluid overload, if their treatments are delayed after the disaster [5]. Although dialysis units must have emergency generators and water tanks, a contingency plan to move patients to another center should be prearranged in case the unit majorly suffers and is rendered nonfunctional after the storm. A few days after the hurricane we lost access to tap water and had to move all our patients to the dialysis unit at Adult University Hospital. Because of the physical proximity and previously established agreements with the institution, we were able to move our entire team, including nurses and nephrologists, which made the transition easier.

\section{Access to Dialysis}

Disruption of transportation services and undriveable roads due to floods, trees blocking lanes, and downed electrical lines could represent a challenge for patients to get to their dialysis units. One of the major crises that we experienced in the wake of hurricane Maria was a shortage of fuel. This affected patient transportation services and personnel. Because we are the only pediatric dialysis unit in the island, some patients must drive up to $3 \mathrm{~h}$ for their dialysis treatments. During the preparation phase we decided to proactively admit 2 patients to the hospital who lived in vulnerable areas and could encounter transportation problems. That proved to be a smart decision as roads to the areas where these patients live were blocked for days after the hurricane. 
Table 1. Emergency preparedness checklist for dialysis units

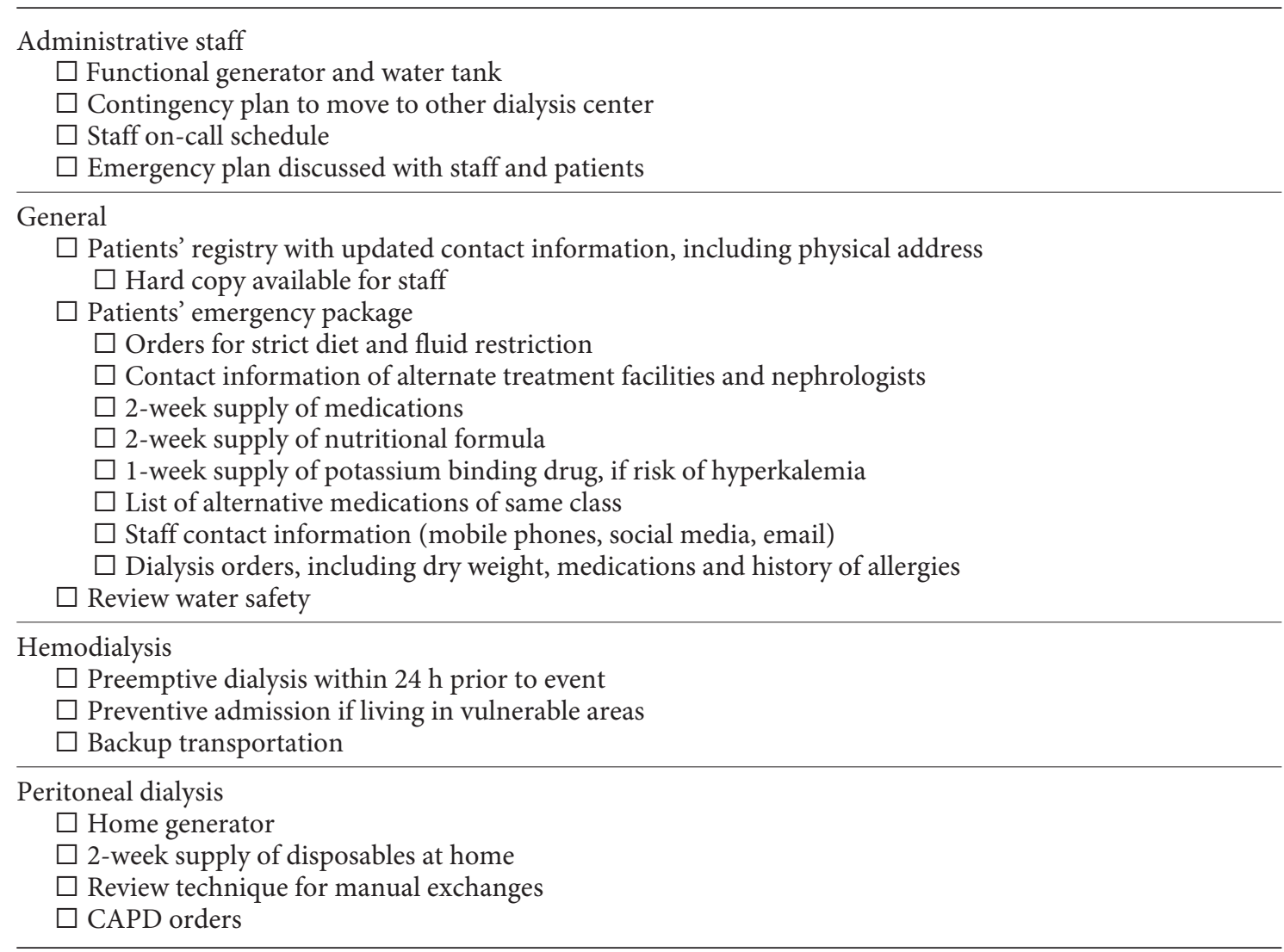

Missing dialysis sessions increases morbidity and represents a threat to patients' lives. A study of the experience with hurricane Katrina showed that $44 \%$ of hemodialysis (HD) patients missed at least one dialysis session and $17 \%$ missed at least 3 sessions. An increased rate of hospitalization was reported in patients who missed at least 3 sessions. They identified that living alone, a dialysis dwell of less than 2 years, moving into a shelter, low compliance with HD treatments in the 3 months prior to the event, and poor knowledge of the dialysis unit emergency plan were risk factors for missing dialysis sessions after the hurricane [6].

A few days after the hurricane, the government of Puerto Rico instructed dialysis patients to seek treatment at the dialysis unit closest to them, regardless of whether they were previously patients there or not. However, due to a complete loss of the communication system, it was difficult to share the message. Again, this underscores the importance of giving patients clear instructions before the hurricane, including contact information for alternative dialysis units closer to their location. None of our pediatric HD patients missed a dialy- sis session or died because of the hurricane. Although the death toll for adult dialysis patients is not known yet, it is known that at least 1 patient died because was not able to get to the treatment center. Experience with Hurricane Sandy in 2012 showed increases in emergency room visits, hospitalizations, and 30-day mortality in the dialysis population as a direct result of the hurricane [7].

Of the $52 \mathrm{HD}$ units in the island, 48 of them were able to continue working immediately after the hurricane, although all of them were using generators and water tanks. After a year, $3 \mathrm{HD}$ units are still closed (Fig. 1). However, over 600 dialysis patients moved away from Puerto Rico, primarily to Florida [8]. This represents a challenge for the receiving units, as they must provide care to complicated patients with very little information and without having the benefit of a coordinated transfer of care. To address this, all dialysis patients should receive copies of their dialysis orders, medications, diet, allergies, and any additional important information at least $48 \mathrm{~h}$ before a major hurricane [9]. Preemptive evacuation should be 


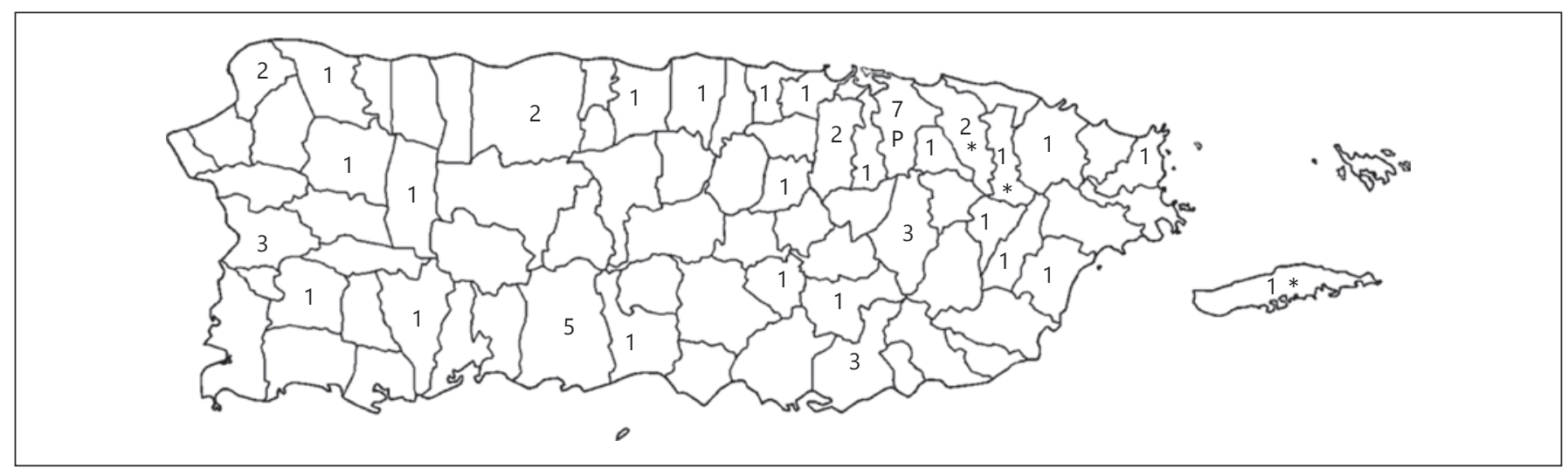

Fig. 1. This map of Puerto Rico shows the location of the 52 dialysis units throughout the 78 municipalities of the island. The numbers indicate the number of units in each municipality. There is only 1 pediatric dialysis unit in Puerto Rico (P), located in San
Juan. One year after the hurricane, 3 dialysis units are still closed, identified by the asterisk $(*)$, located in Carolina, Canóvanas, and Vieques ( 1 on each town). considered for patients living in vulnerable areas and those who have limited mobility, since these patients will represent a challenge for emergency rescue once the hurricane makes landfall.

Attendance of hospital and unit staff represented another difficulty. Like the rest of the population, personnel suffered damage to their houses and had to assist their families. Some lived in vulnerable areas and were trapped in their neighborhoods. The fuel crisis, one of the major problems in the immediate recovery period, forced continuous revisions of the staff and resident call schedule. Although all gas stations had a designated line for emergency personnel, including nurses and physicians, waiting times were still around $2-4 \mathrm{~h}$ in most instances. Lack of electric power disrupted traffic lights throughout the island, worsening traffic conditions. For the safety of our patients and staff, we had to modify the call schedule to guarantee that everyone could return home safely before dusk. To ensure availability of emergency dialysis staff in the immediate post hurricane period, on-call personnel can remain onsite in the dialysis unit during the hurricane, as long as it does not represent a security threat for them. This is more feasible for hospital-based units.

\section{Communication}

Communication was significantly limited. Thus, providing patients preventive education with clear instructions about strict fluid and dietary restrictions, and the possible use of potassium binding resins if they cannot reach a dialysis unit is of the utmost importance. A list of acceptable alternative drugs of a similar class, which could be used if patients are not able to fill their medications, is required. Internet and social media proved to be invaluable communication tools. Although fragile, it was better than radio or television. In the immediate period after the hurricane, only one radio station on the island remained functional. Having an organized WhatsApp group for staff made communication easier. The application was also widely used for communication with patients and other healthcare providers. Analog phone lines are extremely useful and more reliable than mobile cell phones. This service was never interrupted.

It is mandatory to have a formal registry of all patients that includes their updated contact information, as well as contact information for relatives able to reach them. A hardcopy should be kept accessible to the staff since electronic medical records may not be functional. The physical address where an emergency rescue team can be dispatched to find each patient, if needed, is essential. This was life-saving for children with ESRD in Houston after hurricane Harvey [10]. Ideally, with the consent of the patients, every municipality and local emergency agencies should have a registry of all patients with serious chronic illnesses in their community who would likely require additional assistance during emergencies [5]. To inform and support community partner emergency preparedness, the United States Department of Health and Human Services has developed an Internet tool that identifies Medicare beneficiaries who rely on electricity-dependent medical equipment [11]. 


\section{Electric Power and Water}

Patients receiving peritoneal dialysis (PD) at home usually do better after natural disasters than HD patients [12]. Lack of electricity and tap water increases the risk for peritonitis. Social workers play a major role in identifying funds to assist patients obtaining generators. Prior to the event, education - including reviewing the technique for manual exchanges - and providing patients with a prescription for continuous ambulatory PD if they do not have electric power is essential. Although some of our patients had generators, the shortage of fuel forced most of them to use manual exchanges. As a consequence, we observed 3 episodes of bacterial peritonitis in the immediate post-hurricane period. Lack of tap water represents another obstacle. Water safety should be reinforced because as water supplies diminish, people start using natural sources like rivers, creeks, and lakes for bathing and laundry, increasing the risk of contamination. Patients on PD should not use these water sources. Despite proper education during the PD training, one of our families started using water from a local creek for all their needs, including our patient's daily bath and care of the catheter exit site. Water for dialysis patients should meet Environmental Protection Agency drinking water standards. As a general rule, if the water is safe for consumption, then it may be used [13]. All PD patients should have enough disposable supplies for at least 2 weeks stored in a safe place at home. Although we were able to contact all our HD patients within $48 \mathrm{~h}$, it took us 9 days to reach all our PD patients.

The two leading causes of chronic kidney disease (CKD) in the adult population - diabetes and hypertension - are at risk of getting uncontrolled after natural disasters due to inability to follow an appropriate diet, limited accessibility to medications, and poor communication with providers [14]. This was observed in our community, as physicians were forced to close their practices due to lack of electricity and potable water or direct damage to healthcare facilities.

In the pediatric population, our experience showed that patients with congenital abnormalities of the kidney and urinary tract and neuropathic bladders are particularly vulnerable. Some of the patients, either lost their disposables due to direct damage from the hurricane or had to leave their home and move to a shelter during emergency situations, limiting their ability to continue intermittent catheterization protocols. In addition, overcrowding and the poorly sanitized environment in shelters increase the risk of contamination and urinary tract infections. Patients with advanced stages of CKD (stages 4 and 5) are at particular risk of deterioration. These patients were not registered on any list and it was difficult to reach them, since information from outpatient electronic records was not available. Three of these patients were admitted to the hospital within 3 months of the hurricane. Patients with nephrotic syndrome, chronic glomerulonephritis, and CKD were not able to get their routine laboratory tests done and had limited access to medication refills and their primary physicians. Some of the patients had to temporarily switch to a different medication of the same class because pharmacies were closed, or they lacked prescriptions for refills. A similar situation with medications and the ability to get laboratory followup affected the transplant population.

\section{Response}

A few days after the hurricane, our institution started receiving humanitarian assistance from the private sector, nonprofit organizations, and children hospitals in the United States. Most of the donations were hospital supplies and medications for adults and children. We received countless donated supplies that the hospital storage was completely loaded, and we had to convert our conference rooms into a collection center. Eventually, we became a distribution center for many response teams and other healthcare facilities in Puerto Rico. A team of medical and pharmacy students played an instrumental role managing our collection and distribution center as they organized a computerized inventory, keeping a strict registry of all received and distributed supplies. This not only guaranteed the judicious use of all the donations but also allowed us to recognize the contributions of each donor. For at least 2 months, our hospital became a primary hub for providing medications to patients, since many pharmacies were closed.

Exacerbation of preexisting psychiatric conditions due to anxiety, difficulties in their daily living activities, and inability to maintain pharmacotherapy is frequently observed after natural catastrophes [15]. This could lead to poor compliance with therapy, increasing the risk of this highly vulnerable population.

After a major natural disaster like hurricane Maria, with a very slow recovery, the continuous reassessment of needs and response plans is critical. Our collection/ distribution center became our headquarters, where the different working groups gathered and celebrated meetings to discuss strategies and ensure that efforts were not 
duplicated. An old plain blackboard with a map of Puerto Rico was instrumental to maintaining communication between the different responders, our staff, and coordinating efforts with external resources. As we face a new hurricane season still recovering from the devastation left by hurricane Maria, we ought to continue developing strategies to reduce harm to our patients during natural disasters. Our experience showed us that preparing for the worst is not enough. Advance planning of a streamlined response is the best tactic to decrease harm.

\section{Acknowledgment}

We thank Mrs. Angela Díaz, Executive Director of Consejo Renal de Puerto Rico for sharing information and statistics.

\section{References}

1 Staletovich J: Final Numbers on Maria on Puerto Rico: $\$ 90$ Billion in Samage, Some Cat 5 Winds Miami, WLRN; 2018. http://www. wlrn.org/post/final-numbers-maria-puertorico-90-billion-damage-some-cat-5-winds (cited September 1, 2018).

2 Hedges JR, Soliman KFA, D’Amour G, Liang D, Rodríguez-Díaz CE, Thompson K, Romaguera J, Rabionet Sabater SE, Yanagihara R: Academic response to storm-related natural disasters-lessons learned. Int J Environ Res Public Health 2018; 15:E1768.

3 Kishore N, Marqués D, Mahmud A, Kiang MV, Rodriguez I, Fuller A, Ebner P, Sorensen C, Racy F, Lemery J, Maas L, Leaning J, Irizarry RA, Balsari S, Buckee CO: Mortality in Puerto Rico after Hurricane Maria. N Engl J Med 2018;379:162-170.

4 Milken Institute School of Public Health, Editors. Ascertainment of the Estimated Excess Mortality from Hurricane María in Puerto Rico. Washington, The George Washington University, 2018. https://publichealth.gwu. edu/sites/default/files/downloads/projects/ PRstudy/Acertainment\%20of\%20the $\% 20$ Estimated $\% 20$ Excess $\% 20$ Mortality $\% 20$ from $\% 20$ Hurricane $\% 20$ Maria\%20in $\% 20$ Puerto\%20Rico.pdf (cited August 30, 2018).

5 Dent L, Finne K, Lurie N: Progress in emergency preparedness for dialysis care 10 years after Hurricane Katrina. Am J Kidney Dis 2015;66:742-744.

6 Anderson AH, Cohen AJ, Kutner NG, Kopp JB, Kimmel PL, Muntner P: Missed dialysis sessions and hospitalization in hemodialysis patients after Hurricane Katrina. Kidney Int 2009;75:1202-1208.

7 Kelman J, Finne K, Bogdanov A, Worrall C, Margolis G, Rising K, MaCurdy TE, Lurie $\mathrm{N}$ : Dialysis care and death following Hurricane Sandy. Am J Kidney Dis 2015;65:109115.

8 GFR Media, editors: 600 Pacientes de Diálisis Fueron Trasladados a EE.UU. por los Huracanes. San Juan, El Nuevo Dia, 2018. https:// www.elnuevodia.com/noticias/locales/nota/ 600 pacientesdedialisisfuerontrasladadosaeeuuporloshuracanes-2415450 (cited August 30, 2018).

9 Gibney RT, Sever MS, Vanholder RC: Disaster nephrology: crush injury and beyond. Kidney Int 2014;85:1049-1057.
10 Jeltsen M, Campbell A, Editors: Inside The "Impossible" Mission To Rescue 33 Kids Desperate for Dialysis During Harvey. Huffingtonpost, 2017. https://www.huffingtonpost.com/ entry/inside-the-rescue-mission-of-33-children-in-need-of-dialysis-during-harvey us_59a8e389e4b0b5e530fd8beb (cited August 30, 2018)

11 HHS.gov: Washington, U.S. Department of Health and Human Services; c2015.https:// empowermap.hhs.gov (cited August 30, 2018).

12 Kleinpeter MA: End-stage renal disease use in hurricane-prone areas: should nephrologists increase the utilization of peritoneal dialysis? Adv Chronic Kidney Dis 2007;14:100-104.

13 Center of Diseases Control. Atlanta, Safe Use of "Tanker" Water for Dialysis, c2015-2014. https://www.cdc.gov/disasters/watertanker. html (cited August 30, 2018).

14 Lopez-Candales A, Hernandez-Suarez DF, Osterman-Pla AD, Conde-Santiago JG: A reminder from the Devastation Hurricane Maria left behind. Cureus 20188;10:e2038.

15 Sever MS et al: Features of chronic hemodialysis practice after the Marmara earthquake. J Am Soc Nephrol 2004;15:1071-1076. 